Article

\title{
Framework Conditions and Potential Measures for Small Electric Vehicles on a Municipal Level ${ }^{\dagger}$
}

\author{
Amelie Ewert* ${ }^{(\mathbb{D}}$, Mascha K. Brost and Stephan A. Schmid(D) \\ German Aerospace Center (DLR), Institute of Vehicle Concepts, Pfaffenwaldring 38-40, 70569 Stuttgart, \\ Germany; Mascha.Brost@dlr.de (M.K.B.); Stephan.Schmid@DLR.de (S.A.S.) \\ * Correspondence: Amelie.Ewert@dlr.de \\ + This paper is an extended version of a paper presented at 32nd International Electric Vehicle Symposium 2019 \\ (EVS 32), Lyon, France, 19-22 May 2019.
}

Received: 25 October 2019; Accepted: 10 December 2019; Published: 18 December 2019

\begin{abstract}
Responding to pressing problems arising from growing urban populations and mass motorization, municipalities need to take action. The resulting conditions include congested cities, poor air quality and quality of life. Providing contextual conditions and thereby increasing the amount of small electric vehicles could help reduce land use and improve air quality. Based on outcomes of expert interviews and an online survey, the status-quo of antecedences and barriers as well as potential measures for the implementation of small electric vehicles on a municipal level is outlined. To get an international and comprehensive view, experts from the USA, Asia and Europe participated. Results show that there are several obstacles that have to be overcome on local, national and international levels. For local policymakers especially, there is an array of measures available. The combination of push and pull measures is one key element. In this way, infrastructural changes, financial incentives, strategic implementations and soft measures to raise awareness could help the process of a market take-off immensely.
\end{abstract}

Keywords: small electric vehicles (SEVs); light vehicle; mobility concepts; policy; market development; mixed method

\section{Introduction}

Looking at cities around the world today, the progress of congested and cramped landscapes is amplified by ever-growing urban populations and ongoing mass motorization. Land consumption of stationary and flowing traffic is at its limit of capacity and thus reflects in poor urban quality. Further environmental problems such as air pollution are increasingly urgent and are now being addressed in many parts of the world [1,2]. A number of strategies already exist to promote the substitution of vehicles with internal combustion engines (ICE) for those with electric motors. Nevertheless, a low occupancy rate, especially in passenger transport, indicates that there is a need for new vehicle concepts in urban traffic. In this way, it would be possible to make better use of the limited space available in cities and create attractive city centres. Due to their small size small electric vehicles (SEVs), for example, require considerably less parking space than many traditional cars. As a controversial trend sales numbers and available models of larger vehicles i.e., large cars or SUVs grew significantly over the past years [3]. In general, they use more energy than small and light vehicles and become less efficient with regard to their transport task (the vehicle occupancy rate in passenger transport in Europe is at 1.45 [4]). Besides the benefits that come with the deployment of battery electric vehicles (BEVs), small electric vehicles (SEVs) furthermore require less critical raw materials for the production of batteries and overall emit fewer greenhouse gases (GHG) than large electric vehicles or vehicles with ICEs [5,6]. 
World markets show different market uptakes whereas in most countries SEVs have only limited success. Different rules for homologation complicate comparison of these markets and the introduction of vehicle models into new markets. The aim of the study is to discover prospects for SEVs and obstacles that stand in the way of market expansion. Based on this, measures are identified and discussed. During the analysis of finding out the scope for action and the effectiveness of different actors, municipalities turned out to be very influential. Their goals, as well as actions, determine significantly how mobility is formed and thus create the quality of the urban environment. In the analysis, the question of what policymakers can achieve and what scope for action they have is explored.

\section{Situation and Definition of Small Electric Vehicles (SEVs)}

In the context of this paper and our research, SEVs refer to three- and four-wheeled vehicles with all-electric drive limited to a length $\leq 3.5 \mathrm{~m}$, a maximum drive power of $55 \mathrm{~kW}$ and an unladen weight $\leq 1200 \mathrm{~kg}$. According to the European Union (EU) Regulation 168/2013 [7], this includes L-category vehicles (L2 $e, \mathrm{~L} 5 e, \mathrm{~L} 6 e$ and L7 $e$ ) and micro and subcompact electric vehicles (M1) that are laid out in 2007/46/EC [8]. Worldwide the definition and specifications of vehicle classes in the research scope vary depending on the regional area. This complicates the overview and leaves SEVs non-transparent in an international context.

Comparing different world markets including Asia, Europe and the United States sales and stock numbers show a divergent picture. China is a booming market for SEVs with 50 million electric three-wheelers and an estimated five million low-speed electric vehicles (LSEV) (The specifications for the category of low-speed electric vehicles in China are four-wheels and a maximum speed of 40-70 kph [3].) in 2018. The high figures are due in particular to the restricted registration of cars (e.g., license-plate lottery or auctions) as LSEVs do not fall into this category [9]. The vehicles are largely prohibited on public roads. As they raised many safety concerns, production was curbed by the government at the end of 2018 and will be subject to stricter regulation in the future. In the same year India, which is another large market for three-wheeled vehicles shows stock numbers of 2.38 million [3]. In comparison, sales numbers in Europe and the USA show hardly any significant increases in respect to three- and four-wheeled electric vehicles. Figure 1a displays the sales within the EU from 2009 to 2014 and reveals that three-wheeled SEVs (L2 e(3 W MP) elec and L5 e(3 W) elec) are even less sold than four-wheeled electric vehicles (L6_L7 4 W) elec). With regard to four-wheeled vehicles, more recent figures show since 2011 only 30,450 four-wheeled SEVs were sold in Europe, with France and Italy being the main markets (see Figure 1b). These figures show that although these vehicles are widely used in some markets, they are hardly represented in others.

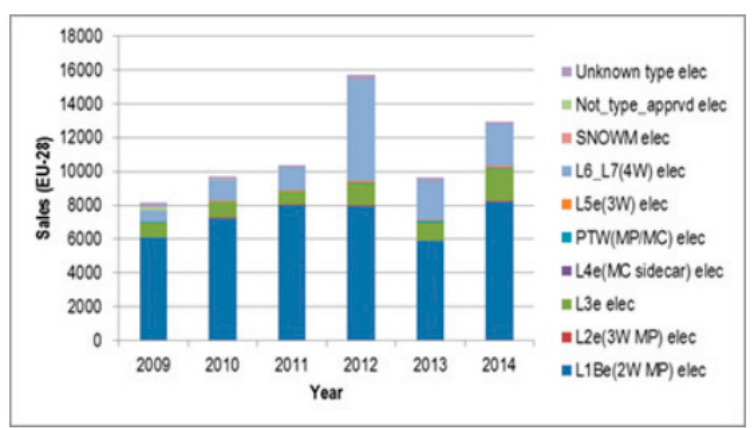

(a)

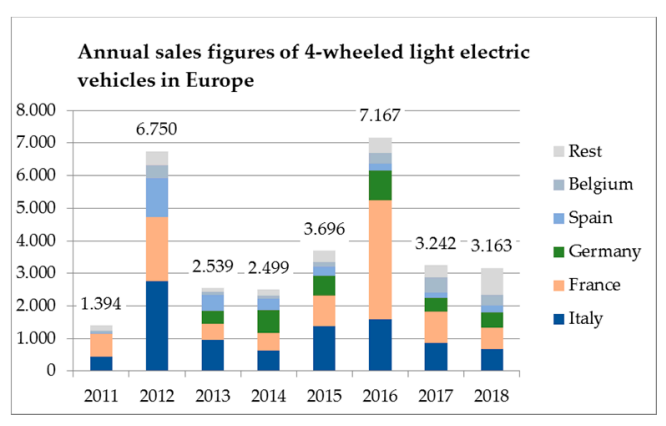

(b)

Figure 1. Annual vehicle sales in Europe: (a) L-vehicles with electric motor by class on the period 2009-2014 of EU-28 countries [6]; (b) Four-wheeled electric L-category vehicles on the period of 2011-2018 in Europe (own visualization, data from [10]). 
In addition to sales figures, the number of available market models is an indication of the success of vehicles. While the market for electric cars continues to grow, the number of models on the market is also increasing. This is different regarding SEVs, where many concept studies were shown on various motor shows or in press releases like the Opel RAK $e$, VW NILS, Honda New Electric Urban Vehicle or Citroën Ami One but only a few models are available on the market. While most of the manufacturers are smaller companies or startups models from large OEMs include the Renault Twizy or the Toyota i-Road and COMS.

\section{Materials and Methods}

For the main analysis, an as-is analysis of the markets to be considered later was first carried out. For the markets Asia, Europe and the United States, secondary data and literature were collected by desk-based research. In addition to the stock and sales numbers, applications, as well as use cases and already implemented measures in favour of SEVs, were identified (see Figure 2).

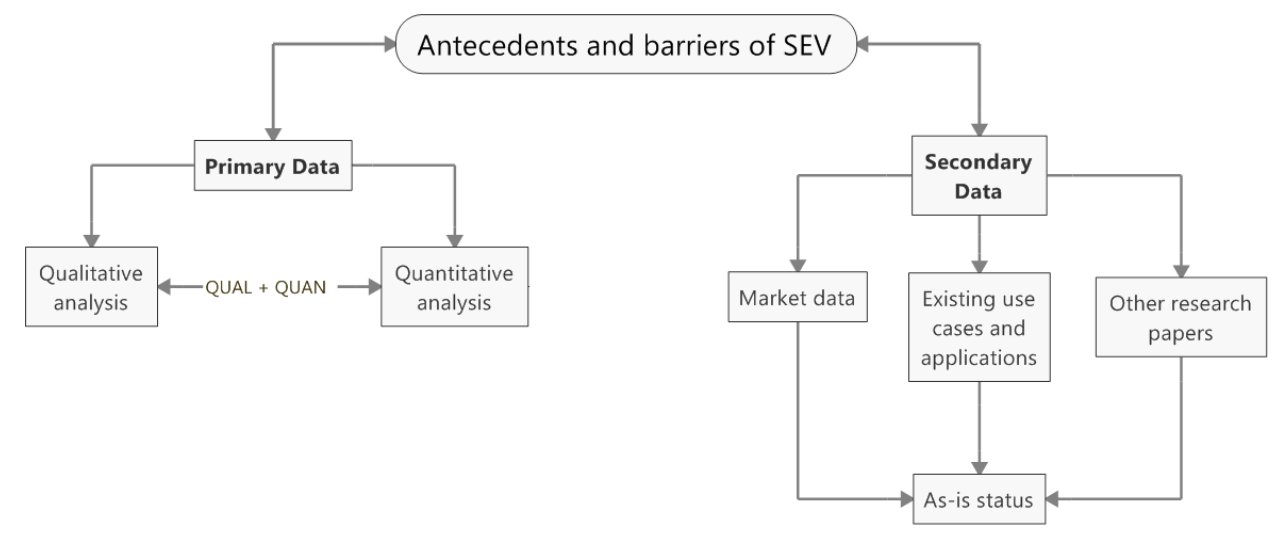

Figure 2. Approach of the mixed-method analysis and as-is analysis (own visualization).

The main analysis comprises primary data accumulated from quantitative and qualitative empirical social research. For the qualitative method, expert interviews were conducted with professionals from different backgrounds. The aim was to get insight and exclusive knowledge that was gained from practical application, experiences or research. Simultaneously, for quantitative research, a standardized online survey was carried out with the same target groups. With a mixed-method-design, the outcomes of both research methods were combined in a concurrent triangulation. The approach of comparing outcomes from questionnaires and interviews is mostly common in the disciplines of medicine and psychology but is also applied in education, information technology or religious studies [11]. Despite separating the methods the same research questions are applied and according to Morse (1991) follow the parallel design QUAL + QUAN [12]. A comparison of data collected from both methods reveals similarities, divergences or additional information and thus ensures higher validity. Finally, meta-inferences can be formed by comparing the results. Together with the desk-based study an outline of different views and prospects for urban mobility today as well as in the near future can be drawn.

Questions for the qualitative and quantitative analyses were divided into three topics: "Knowledge about SEV", "Target group and utilization concepts" and "Obstacles and chances". Within the topic of obstacles and chances, a large part was dedicated to different measures and their effectiveness.

The evaluation of the semi-structured expert interviews is based on a concept of Meuser and Nagel (2005) and follows the approach of qualitative content analysis. This is subject to the Grounded Theory, in which successive categories are formed and related to each other through the repetitive process of data analysis (see Table 1). The content from the interviews is coded by paraphrasing individual text passages which are concordant in content. They are classified thematically with categories which are congruent with the key questions. Further sub codes comprise partial aspects. Then statements can be 
compared and conceptualized. Ultimately, a theory is created by inductively generalizing statements on the basis of individual findings [13-15].

Table 1. Example of a theoretical generalization according to Meuser and Nagel (2005).

\begin{tabular}{|c|c|c|c|}
\hline Category & Citation & Paraphrase & Generalization \\
\hline $\begin{array}{l}\text { Knowledge about SEV in } \\
\text { the urban population }\end{array}$ & $\begin{array}{l}\text { In recent years, the interest in } \\
\text { the use of SEV is increasing } \\
\text { due to the difficulty of parking. } \\
\text { We register a strong interest } \\
\text { for electric bicycles, e-scooter } \\
\text { and micro car for sharing. } \\
\text { Europe } \backslash \text { Mu02: } 10-10(0)\end{array}$ & $\begin{array}{l}\text { Pressing problems along } \\
\text { with density lead to a } \\
\text { higher interest in SEVs. } \\
\text { Urban cores and old } \\
\text { town with narrow streets. } \\
\text { (Mu02) }\end{array}$ & $\begin{array}{l}\text { SEVs are well known in } \\
\text { the urban population }\end{array}$ \\
\hline
\end{tabular}

As shown in Figure 3, in total 32 interviews were conducted and 90 participants contributed to the online survey including experts from municipalities, consultants, research institutes, manufacturers and associations.
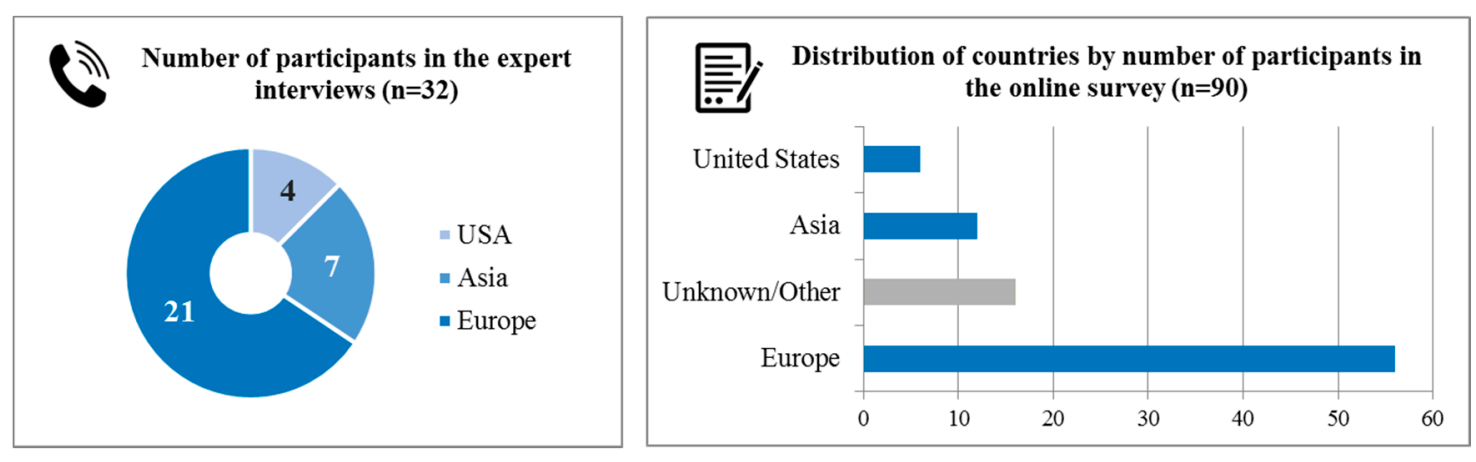

Figure 3. Number of participants of expert interviews and the online survey distributed by regional background (own visualization and data).

For both methods, the results are not representative due to the limited number of experts and thus the answers from the respective countries. Since a large part of the information came from experts in Europe (see Figure 3), more solid statements can be made here. In general, the results should only give a general overview of the current situation. The scope of the analysis is furthermore limited to passenger transport within urban surroundings. The focus is on municipalities and excludes other actions carried out by different stakeholders.

\section{Prospects and Potential Utilization Concepts for SEVs}

The following subsections comprise analyses from both expert interviews and the online questionnaire. First, important prospects for more SEVs in cities are identified. Furthermore, barriers that stand in the way of a market uptake are presented. Then potential utilization concepts, as well as target groups, are presented and discussed.

\subsection{Major Barrier: Missing Knowledge about SEVs}

The most important aspects according to respondents of the survey and the interviews comprise efficient use of space and better air quality (see Figure 4). This transforms urban areas into one of the most relevant playgrounds for this type of vehicle. In particular, stationary traffic, which accounts for vehicles for up to $95 \%$ of the day [16], became one of the main drivers for the need to support SEVs. Other prospects that are seen as effective and directly linked to the city are noise reduction and increased urban and life quality. The comprehensive feedback makes it clear that the municipalities themselves are influential actors and could initiate many measures to overcome obstacles that stand in the way of a market breakthrough. 


\section{Important prospects for more SEVs in cities \\ (Multiple Choice*, $\mathrm{n}=84$ )}

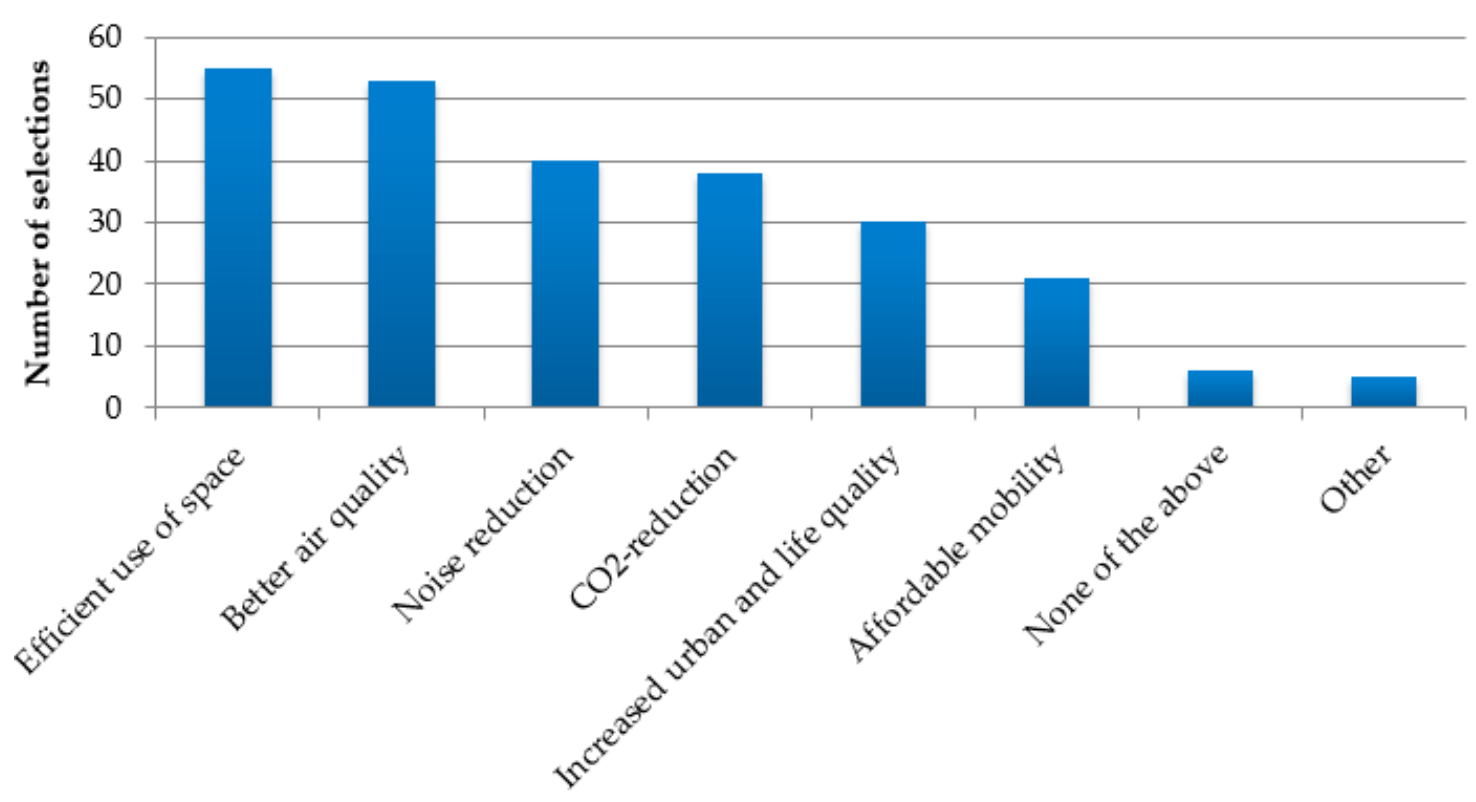

*Participants'were·able·to·check·three'prospects. I

Figure 4. Prospects that are important resulting from the deployment of small electric vehicles (SEVs) in cities (own visualization and survey data).

Although uptake of SEVs would have many positive impacts for cities, they are not well-known among the urban population or the municipal administration themselves. E-bikes, electric motorbikes and above all the current emerging market for micro electric vehicles show that small vehicles are accepted. However, according to experts from Europe and the United States, this does not apply to the segment's three-wheeled and four-wheeled vehicles. Furthermore, these vehicles are commonly not considered as an option for sustainable transport and are classified as too unsafe or unattractive. For this reason, getting the concept closer to the cities is the first step. In this context, the benefits that can result from the deployment should be highlighted specifically.

\subsection{Potential Utilisation Concepts and Target Groups}

In the discussion about viable user concepts, particular attention was paid to the demands of cities and the most sustainable solutions possible. The potential utilization concepts for passenger transport queried in the online survey are displayed in Figure 5.

Tourist services are seen as the most promising utilization concept (89\%). In this way, short distances between the sights can be efficiently managed and tourists maintain the flexibility to travel on their own schedule. Fleets such as company or campus fleets (85\%) are also seen as promising. According to most of the experts in the interviews but also in the survey (83\%) sharing schemes are a good concept and named it the most important model for today's cities in particular operated with SEVs.

Private use and commuters are a reasonable target group especially in cities where ownership of a car is still dominant. Although private ownership is seen as overall promising by $72 \%$ and only $45 \%$ as very to fairly promising, in comparison, they are seen as the least promising. Nevertheless, it is important to examine which modes of transport are being replaced. 


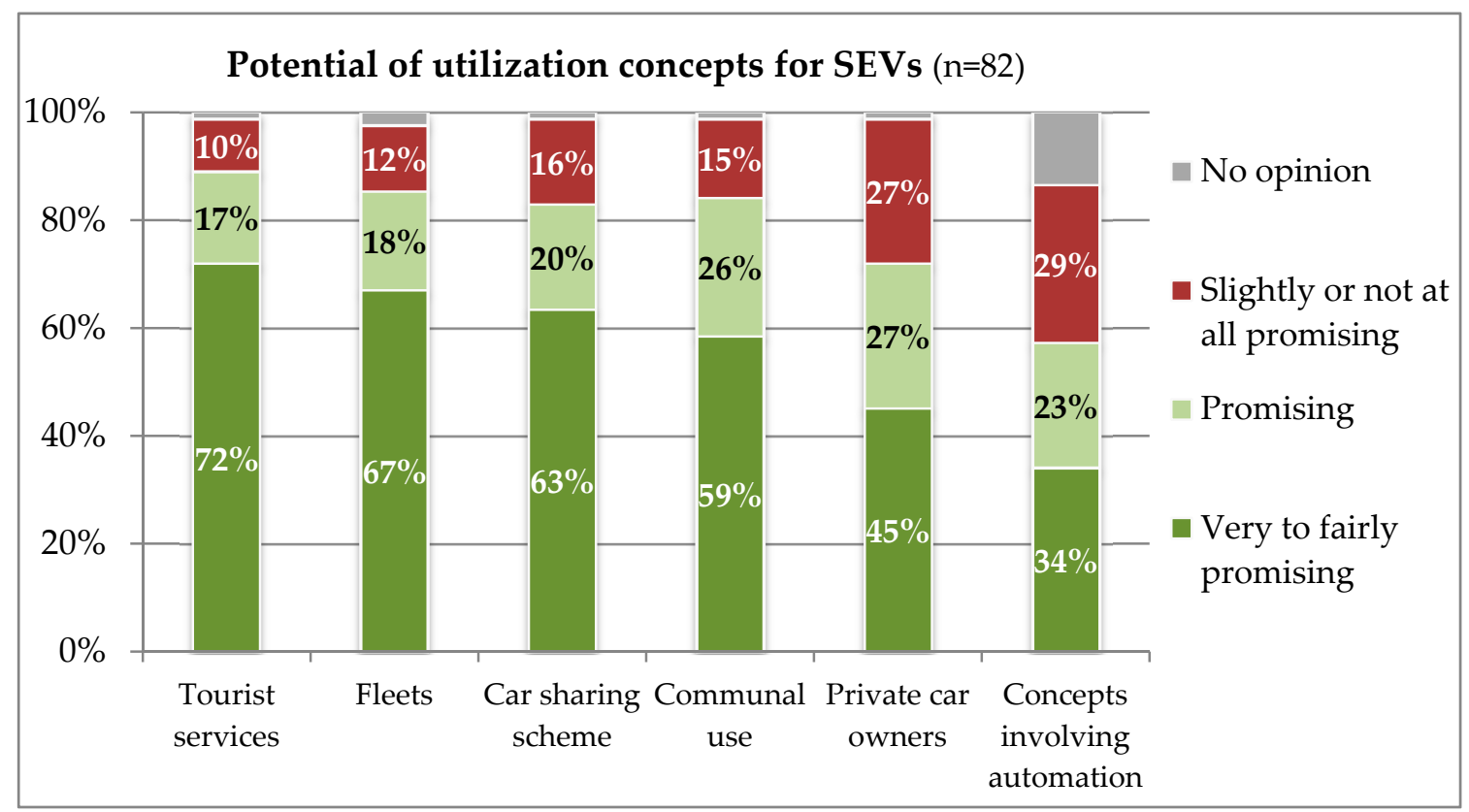

Figure 5. Estimated potential of different utilization concepts for SEVs (own visualization and survey data).

\section{Obstacles for a Market Uptake of SEVs}

There are several hurdles in the way of promoting SEV in cities. While some of the aspects apply to all regions under consideration, some show clear differences in severity in terms of barriers to market expansion. For both Europe and Japan, the mind-set within the society regarding car ownerships and the industry was considered as a strong opponent. In Europe, the lack of a sufficiently large range of models, knowledge within the urban population and municipalities as well as the available information. Furthermore, the relatively high purchase price is seen as particularly problematic. Due to the higher number of experts interviewed, more hurdles are mentioned in comparison to the other regions (see Figure 6). In China, on the other hand, other problems apply, such as the lack of regulation for usage and production of low-speed electric vehicles (LSEV) until 2019. In addition, the vehicles are considered to be a means of transport for older people and therefore attract only a certain target group. Safety is one large concern for Europe and China. In China, due to the lack of regulations and the possibility, e.g., due to low income or lottery systems, most of the vehicles produced have poor quality. LSEVs are therefore cheap but offer minor vehicle safety. In Europe, significantly higher-quality vehicle models are being developed, but no crash test requirements are legally mandatory in the L-category [17]. For this reason, manufacturers are in conflict to increase safety requirements and thus to develop a safer but also more expensive vehicle. With regard to the United States, the adaptation of policy and regulations for the maximum speeds regulated on the roads was unanimously mentioned. These are often very high and either prohibit the use of the vehicles on the road or make the use of the vehicles unattractive. For this reason, they are currently used mainly in defined areas. 


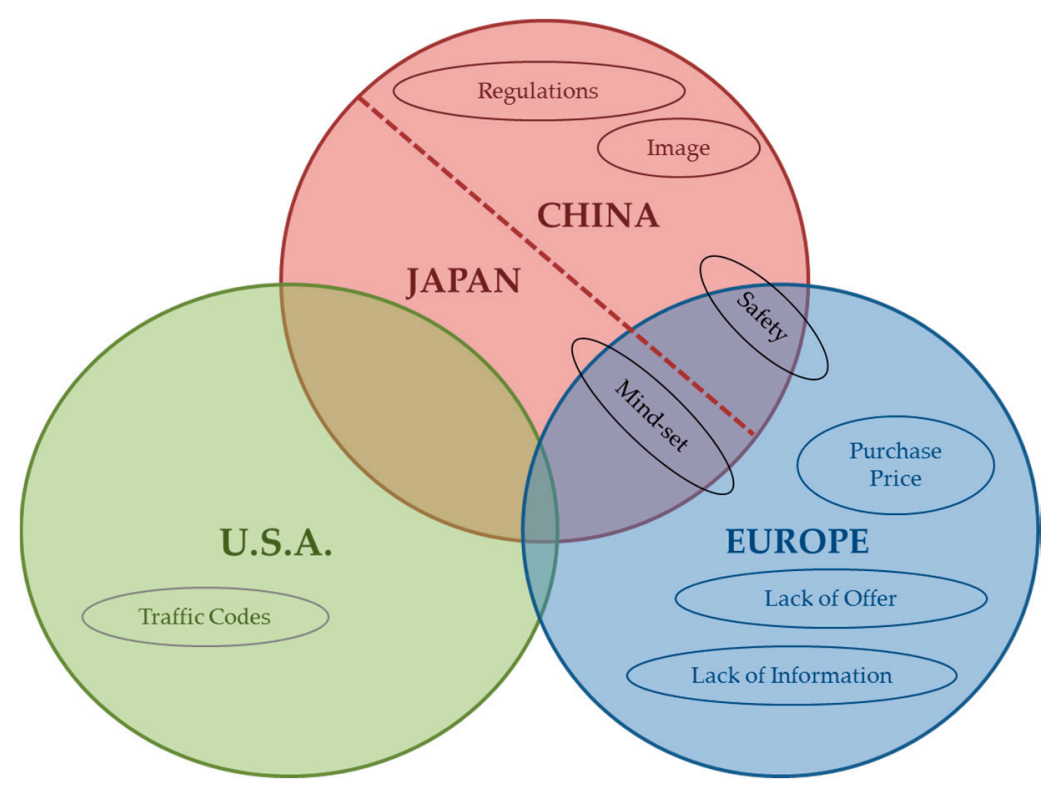

Figure 6. Strong influencing factors that hinder market penetration depending on different regions (own visualization and data from expert interviews).

\section{Measures to Promote an Uptake of SEVs}

On the local level there are several measures that could be implemented to promote the use of SEVs over cars with ICE including push and pull factors.

\subsection{Traffic Infrastructure}

Changes in transport infrastructure include both moving and stationary traffic and may involve regulations, constructional solutions or reallocation of road space. Although the measures presented below are fundamental, they are needed at least in part to make a difference.

\subsubsection{Dedicated Traffic Infrastructure}

Currently, in most of the countries worldwide the ownership of cars is still the dominant form of transportation and is reflected in historically evolved auto-centred cities. In most cities, SEVs have to share space with all other vehicles on the road. This does not give them any advantages, for example, to save travel time by avoiding congestion. Sharing lanes with large vehicles on higher speed roads also leads to greater safety risks. Ultimately, there are no advantages on the road and thus no motivation to switch from a car to a smaller vehicle.

This circumstance is seen as the biggest hurdle to stand in the way of market uptake. Improving the infrastructure in favour of SEVs can increase demand. They have to be separated from other vehicles to avoid traffic jams and to travel safer on the road. However, many cities are already struggling with cramped space and a high volume of traffic that needs to be satisfied. It would, therefore, be more reasonable to share lanes with buses and taxis for the medium term. As soon as the number of vehicles increases, however, the lane should again give priority to buses in order not to favour individual traffic. A good example is Norway, which has been sharing bus lanes with electric cars in general since 2005. This, along with many other incentives, has led to an uptake of electric mobility [18].

Another concept that is emerging is shared space. This approach is intended to enable interactions between road users of any kind to be implemented without traffic regulations. In countries where this is not possible according to road regulations, zones with reduced speed can lead to similar traffic situations [19]. With the upcoming of many different types and sizes of vehicles beginning from personal light electric vehicles (PLEV) up to buses, there is limited space for many separated lanes. 
Setting up shared spaces could increase the safety of different road users. Therefore, every road user including people with disabilities needs to be considered in the design process.

To go even further than only priority access to bus lanes or shared spaces bans in city centres could be applied to ICE vehicles and are seen as highly effective (by $94 \%$, see Figure 6) for their promotion. Furthermore, some streets, especially in inner cities or neighbourhoods, are suitable for a car-free layout with an exception for SEVs. In the long term, an entire ban on cars from city centres can be realized. One effective measure that is already a common tool is (ultra) low emission zones ((U) LEZ). This way people are pushed towards buying electric vehicles (EV) in order to use individual transport in the city centre. However, EVs in general, are often preferred to SEVs. Therefore, there should be specific advantages for SEVs or addition, that certain vehicle sizes are excluded from the city. In the medium term, it is more likely to set up city tolls with reduced tariffs for SEVs until setting up a LEZ.

However, the economic activity affected in the areas must always be taken into account. Alternative mobility offers, such as sharing schemes, can make travel choices more attractive.

\subsubsection{Special Parking Spaces and Parking Management}

Another traffic-related problem is parking in cities. On average, the car remains in a parked position for $95 \%$ of the day [16]. The increasing motorization rate results in extensive land use for parking spaces. Parking pressure also leads to increased parking search traffic, resulting in traffic jams and, in the case of vehicles with internal combustion engines, air pollution in particular. A reduction of parking areas would, however, lead to a significant increase in urban quality. SEVs are small-sized and could, therefore, e.g., substitute a large parking space with two to four lots depending on their size. However, it is crucial to determine parking regulations and precautions. This will help to avoid problems that may arise, such as those caused by bicycle sharing systems such as ofo or Mobike. In these applications, many cities struggled with congested sidewalks or cycle paths.

Through various incentives e.g., special parking spaces, SEVs can be favoured over cars. The experts questioned stated that this would be a very powerful tool to be implemented by municipalities ( $88 \%$, see Figure 7 ). Redesign of smaller parking spaces could be realized in proximity to the workplace, the event location or in residential areas. Furthermore, dead areas can be converted into parking areas, e.g., small street triangles without use. These actions can either come from the municipality alone or be initiated in dialogue by manufacturers wishing to introduce a vehicle to the market.

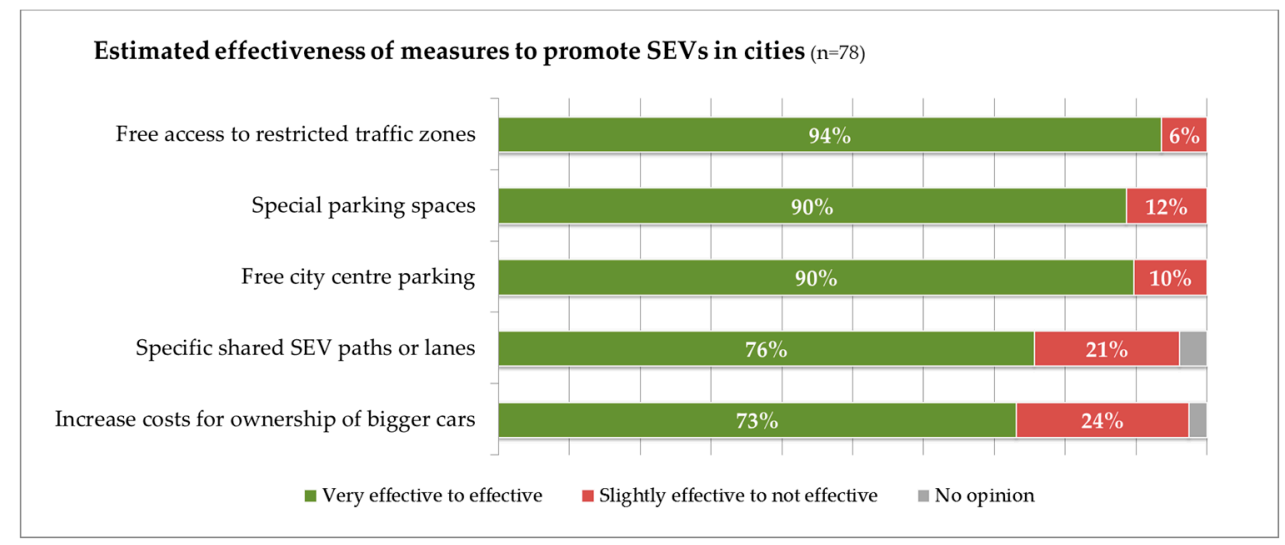

Figure 7. Estimated effectiveness of push and pull measures to promote SEVs in cities concerning parking (own visualization and survey data).

Regulatory permission can be introduced for transverse parking as many SEVs also fit transversely into smaller parking spaces due to their short length. As a third and also very powerful measure seen by $90 \%$ of the respondents, parking management could take effect by requiring SEV drivers to pay 
little or no fees for parking. On the contrary costs for ownership of a car need to be increased and can partly be achieved by increasing or introducing parking rates.

Overall, increasing the cost of car ownership would help to encourage the use of SEVs. Combining these measures provides on the one hand push and on the other hand pull factors, which increases the impact. Push and pull measures are behaviour-changing measures through policy that function in a combination of rewards and incentives on the one hand and punishments on the other. The adjustment of transport planning objectives and strategic goals may be required in order to reach higher scaled effects such as the reduction of the motorization rate. Instruments can be clean air plans, traffic development plans or parking policies. In addition, it is advisable to gradually extend the measures from individual lighthouse projects towards high area coverage [20].

\subsection{Charging Infrastructure}

The limited range of SEVs in comparison to normal BEVs could be a barrier in the buying decision. Consequently, the lack of sufficient charging infrastructure is an obstacle for the market.

In order to have charging security and to take away range anxieties within the urban population, charging infrastructure in cities must be expanded. In this statement, it is particularly striking that the municipalities questioned in the interviews attach high importance to this measure. Additionally, the survey revealed this measure to be the second most important, with $91 \%$ of respondents saying it is effective (see Figure 8). To achieve sufficient coverage public bodies themselves should get involved, but can cooperate with private companies and energy suppliers. Providing charging infrastructure, however, can be a problem for municipalities as it means high resource expenditure.

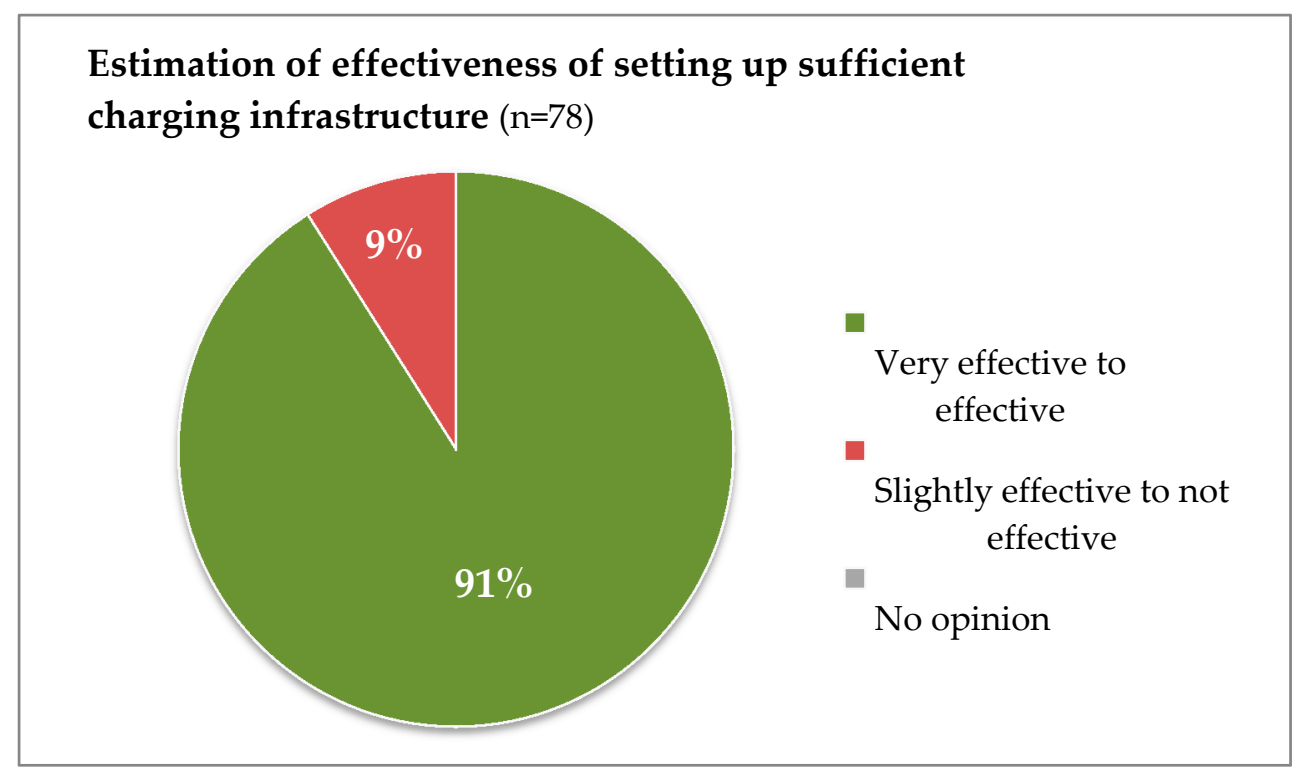

Figure 8. Estimated effectiveness of setting up sufficient charging infrastructure (own visualization and survey data).

\subsection{Adapting Traffic Codes}

In addition to the transport infrastructure measures, municipalities have the possibility to intervene in some aspects through policies or regulations. This does not require large resources but considerable results can be achieved.

Non-adapted or hindering traffic codes are seen in particular in speed limits on the roads. Especially in the United States SEVs are hindered to run in mixed-vehicle traffic with the background that they should only cover short distances in planned communities. These regulations can be widened by the states or even local jurisdictions [21]. This reveals a fragmented landscape of different roadway 
speed limits throughout the country. It would, therefore, be helpful to develop clear regulations in favour of SEVs that are consistent on a larger scale.

Furthermore, it is important to address the speed limits in cities in European as well as in cities of the United States. A large obstacle for the urban population to buy a SEV or for municipalities to foster them is the safety aspect and the lack of required crash tests. Reducing top speed limits in urban centres down to $30 \mathrm{~km} / \mathrm{h}$ would largely increase safety. This hypothesis is demonstrated, among others, by a long-term study in London (1986-2006), which shows the effects of the introduction of $20 \mathrm{mph} / \mathrm{h}$ $(32 \mathrm{~km} / \mathrm{h})$ zones on road safety. According to the study, this led to a $41.9 \%$ decline in the number of road accidents, based on the number of road casualties at that time [22]. Recent studies, such as Aldred (2019) or Sugiyanto (2018), also take up this argument of increased safety at lower speeds in further analyses $[23,24]$.

Another positive aspect is that vehicles with a top speed of $45 \mathrm{~km} / \mathrm{h}$ or less would not hinder traffic as they would in higher-speed limited roads.

\subsection{Financial Incentives}

Costs of SEVs can be high especially when comparing them to e-scooters or pedelecs. The price range lies between approximately 7000 and 55,000 EUR. By providing energy taxation, EV and vehicles that consume less energy have advantages over conventional ICE vehicles. In addition to subsidies from the state, municipalities can take the initiative, as L-category vehicles are not included in all state subsidies. They can provide discounts on charging facilities for citizens or for using public transport in the case of a SEV-ownership. Financial aid was perceived as a powerful tool from the experts in the interviews. This statement is reflected by $76 \%$ of the online questionnaire respondents who assess this measure as very effective to effective (see Figure 9). Financial support for manufacturers is also a measure that could be implemented by municipalities.

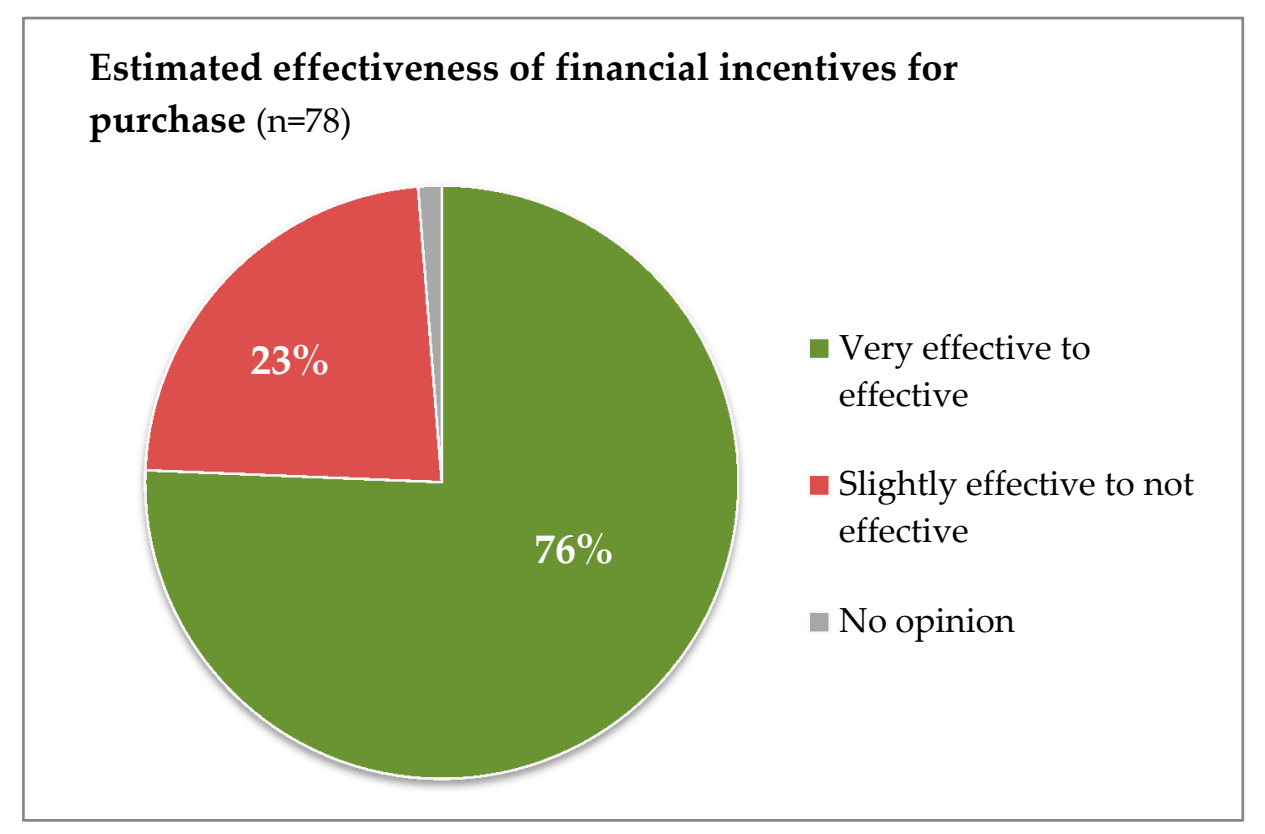

Figure 9. Estimated effectiveness of financial incentives for purchase (own visualization and survey data).

\subsection{Raise Awareness}

In addition to the infrastructural and regulatory changes presented, soft measures are a good incentive to encourage potential consumers towards the use of SEVs. One large factor holding back widespread use of SEVs is the lack of knowledge about these vehicles among the urban population. 
There are only a few use cases, not many vehicles on the road and only a few vehicle models on the market compared to cars. The people who are familiar with these vehicles, however, mostly have the image of an unsafe and visually unattractive vehicle for the elderly. These are obstacles that can be tackled by municipalities in order to reach a wider target group. There are several utilization concepts that can be fostered by actions such as knowledge transfer through municipalities.

\subsubsection{Pilot Projects and Show Cases}

An effective way to make SEVs visible is to deploy them in various pilot projects or showcases. It is an effective way of testing the impact and mechanisms of action with SEVs in operation. In order to set a good example, the public sector can use these vehicles in particular, e.g., for park maintenance. Furthermore, pilot projects can be implemented together with various stakeholders such as companies, transit agencies, universities, manufacturers or Non-governmental organizations (NGOs) and communal organizations.

\subsubsection{Offer Sharing Schemes}

Potentials are also seen in car-sharing within urban areas or for tourist services (by $77 \%$ of the respondents from the online survey). There is already a number of sharing systems implemented in Asia and Europe. In many of the European projects such as Citélib by Ha:mo, RUHRAUTO, Re.volt or ENUU the municipalities are involved in different intensities. By offering this type of vehicle in a non-binding way and over a longer period of time this is a good step to introduce the vehicles to citizens.

\subsubsection{Campaigns and Activities}

In the online survey, a measure that was seen as less effective than other incentives is campaigns and activities by $55 \%$ (see Figure 10). Nevertheless, during the interviews, it became clear that the only way to experience this type of mobility is to test the vehicles. An even smaller hurdle than, e.g., a registration for a car-sharing program is the attendance at various municipal events where these vehicles can be presented. Test drives allow visitors to experience a first contact and the driving feeling. In this way, citizens can receive information about SEVs and their benefits.

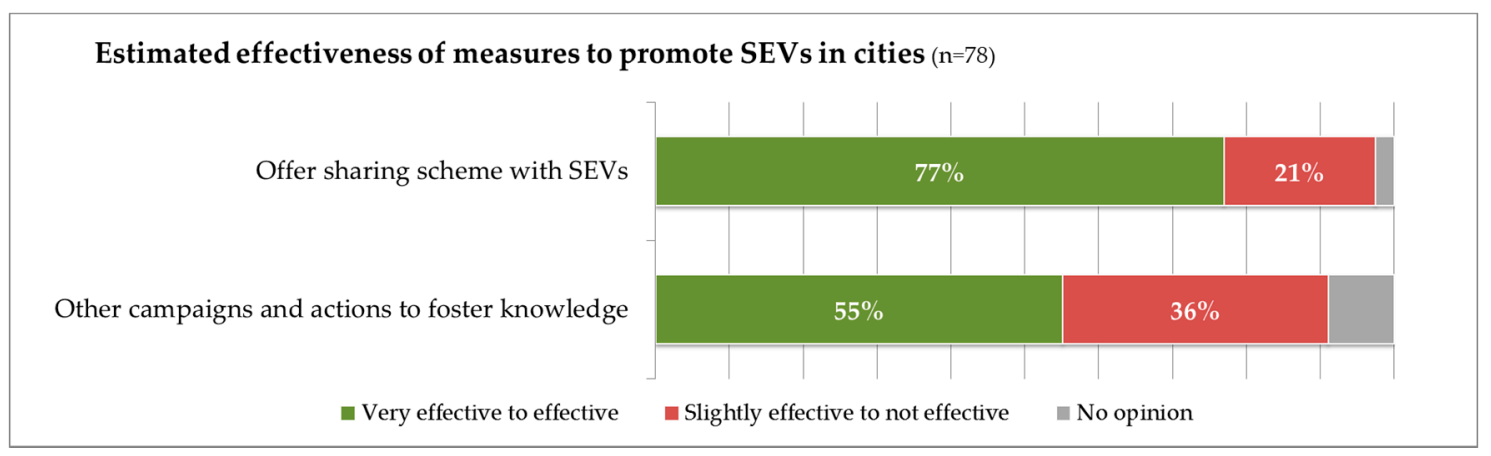

Figure 10. Estimated effectiveness concerning sharing schemes and campaigns to raise awareness (own visualization and survey data).

\section{Discussion}

Looking at potentials and barriers of SEVs the municipal administration and their motivation to promote these vehicles play the key role. In contrast to BEV in the M1 class, they have lower energy consumption in operation due to the lower weight and low speed of the vehicles. With an increased share of LEV's traffic performance in motorised passenger and commercial transport, they could contribute towards climate protection. They require small space per vehicle which leads to the potential use of these areas for other purposes. They, therefore, offer several advantages that attract 
action not only at the global but also at the local level. This article aims at discovering important measures regarding the promotion of SEVs. A direct approach with showcasing of the advantages by different actors is a first step to raise awareness. Once public bodies are eager to promote SEVs, various measures can be implemented at the municipal level. Probably the most important element is the transport infrastructure, which has mostly not yet been adapted. Cities need to think about what place SEVs can and should occupy and accordingly give access to restricted areas or even special lanes and parking spots. The promotion of SEVs is very important on the one hand, but on the other hand, obstacles need to be created for driving vehicles with ICE. In this sense, (U) LEZ, which is already being introduced in some cities, or higher parking fees, have great potential.

Overall, there is a range of measures that can be applied at different levels. However, incentives need to be bundled together in order to have an impact. Some incentives, e.g., setting up charging infrastructure, are already being implemented for EV whereby synergies can be created.

To know which measures to implement in a specific city it is, however, crucial to consider the local and national requirements, regulations as well as the mind-set of the society. Therefore, when promoting SEVs in any kind of way a municipality needs to know about the possibilities it can bring to their city by having its own research. This can, for example, be the calculation of their own official channels when converting fleets. Since cities have many differences it might be possible to create a toolbox with measures as Figure 11 shows and to pick out the feasible tools depending on the city in order to achieve a higher market share.

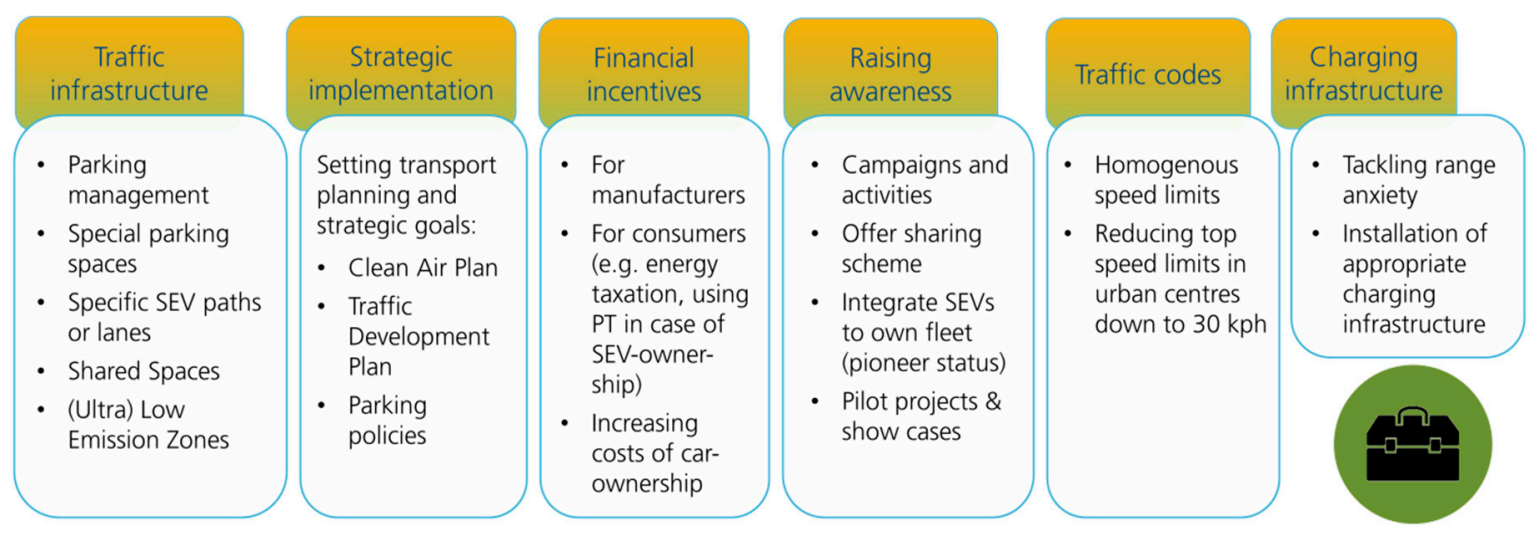

Figure 11. Toolbox with various measures to promote SEVs in the city (own visualization).

The differences in the regions considered play a major role especially in terms of utilization. Although SEVs find their place everywhere in the urban environment, this is interpreted differently in Asian megacities where this applies to the suburbs. Although commuters are the desired group due to the low occupancy rate, they are not a reasonable chance against the background of the change in mobility concepts and the low range. A focus should be laid on first- and last-mile mobility in the form of collaboration between public transport and sharing alternatives with SEVs.

Overall, SEVs are likely to remain a niche market in the medium term as there is little encouragement to buy such a vehicle as long as they are not offered significant advantages from cities. Some of the measures require a large number of resources, but for a start, it is also possible to begin with e.g., strategic implementation and policies. However, some of the measures are not welcomed by certain interest groups such as large manufacturers. It would therefore also take other manufacturers such as Renault with Twizy to produce these vehicles in order to create an effective lobby. The vicious circle where the risk for investors is too high must be minimized by already implemented measures. Only when the costs for SEV are reduced a major breakthrough can come as the price in the purchase decision is one of the key factors that can be influenced.

In conclusion, SEVs are a sustainable mobility solution and could tackle many problems cities face today. By starting the process of awareness and knowledge an initial impulse is given and getting 
municipalities on board could influence the SEV market share substantially. But in order to see success, infrastructural adjustments have to be made in urban traffic.

Author Contributions: Conceptualization, A.E.; Methodology, A.E.; Validation, M.K.B. and S.A.S.; Formal analysis, A.E.; Investigation, A.E.; Resources, A.E.; Data curation, A.E.; Writing-original draft preparation, A.E.; Writing-review and editing, M.K.B. and S.A.S.; Visualization, A.E.; Supervision, A.E. and M.K.B.; Project administration, S.A.S.; Funding acquisition, S.A.S. and M.K.B. All authors have read and agreed to the published version of the manuscript.

Funding: This research received no external funding. The study was realized against the background of the Task 32 in the framework of the International Energy Agency (IEA) which operates a "Hybrid and Electric Vehicle Technology Collaboration Programme" (HEV TCP). The Task is an international working group including members from Europe and Asia on the promotion of SEV headed by the German Aerospace Center (DLR) to advance better market perspectives due to a change in surrounding conditions such as regulations, transport policies and mobility concepts.

Conflicts of Interest: The authors declare no conflict of interest.

\section{References}

1. Ewert, A.; Brost, M.; Schmid, S. Fostering small electric vehicles on a municipal level. In Proceedings of the 32nd Electric Vehicle Symposium (EVS32), Lyon, France, 19-22 May 2019.

2. Meyer, G. (Ed.) Megacity Mobility Culture. How Cities Move on in a Diverse World, Lecture Notes in Mobility; Springer: Berlin/Heidelberg, Germany, 2013. [CrossRef]

3. International Energy Agency. Global EV Outlook 2019: Scaling-up the Transition to Electric Mobility; OECD: Paris, France, 2019. [CrossRef]

4. Layos, F.; Antonio de la, L. Short Distance Passenger Mobility in Europe; European Communities: Luxembourg, Luxembourg, 2005.

5. Honey, E.; Lee, H.; Suh, I.-S. Future Urban Transportation Technologies for Sustainability with an Emphasis on Growing Mega Cities: A Strategic Proposal on Introducing a New Micro Electric Vehicle Statement. World Technopolis Rev. 2014, 3, 139-152. [CrossRef]

6. Santucci, M.; Pieve, M.; Pierini, M. Electric L-category Vehicles for Smart Urban Mobility. Transp. Res. Procedia 2016, 14, 3651-3660. [CrossRef]

7. European Parliament, European Council. Regulation (EU) No 168/2013 of the European Parliament and of the Council; EAA: Oshkosh, WI, USA, 2013.

8. European Commission. 2007/46/EC, L 263/1; European Commission: Brussels, Belgium, 2007; p. 160.

9. Wang, J.; Wu, Q.; Liu, J.; Yang, H.; Yin, M.; Chen, S.; Guo, P.; Ren, J.; Luo, X.; Linghu, W.; et al. Vehicle emission and atmospheric pollution in China: Problems, progress, and prospects. PeerJ 2019, 7, e6932. [CrossRef] [PubMed]

10. ACEM: Motorcycle, Moped and Quadricycle Registrations in the European Union-2010-2018. Available online: https://www.acem.eu/market-data (accessed on 08 March 2019).

11. Harris, L.R.; Brown, G.T.L. Mixing interview and questionnaire methods: Practical problems in aligning data. Pract. Assess. Res. Eval. 2010, 15, 19.

12. Baur, N.; Blasius, J. (Eds.) Handbuch Methoden der Empirischen Sozialforschung, Handbuch; Springer VS: Wiesbaden, Germany, 2014. [CrossRef]

13. Meuser, M.; Nagel, U. Das Experteninterview-Konzeptionelle Grundlagen und methodische Anlage. In Methoden der Vergleichenden Politik- und Sozialwissenschaft; Pickel, S., Pickel, G., Lauth, H.-J., Jahn, D., Eds.; VS Verlag für Sozialwissenschaften: Wiesbaden, Germany, 2009; pp. 465-479. [CrossRef]

14. Saldana, J. The Coding Manual for Qualitative Researchers, 3rd ed.; Arizona State University: Tempe, AZ, USA, 2015.

15. Ullrich, P. Das explorative ExpertInneninterview: Modifikationen und konkrete Umsetzung der Auswertung von ExpertInneninterviews nach Meuser/Nagel. In Die Transformation des Politischen Analysen, Deutungen und Perspektiven; Siebentes und achtes DoktorandInnenseminar der Rosa-Luxemburg-Stiftung; Engartner, T., Kuring, D., Teubl, T., Eds.; Rosa Luxemburg Foundation: Berlin, Germany, 2006.

16. Shoup, D. The High Cost of Free Parking; American Planning Association: Chicago, IL, USA, 2005; p. 18.

17. e-mobil BW GmbH (Ed.) Elektrische Klein- und Leichtfahrzeuge. Chancen und Potenziale für Baden-Württemberg; e-mobil BW GmbH: Stuttgart, Germany, 2019. 
18. Norsk elbilforening, Norwegian EV Policy. Available online: https://elbil.no/english/norwegian-ev-policy/ (accessed on 21 February 2019).

19. Forschungsinformationssystem (FiS). Rechtliche Rahmenbedingungen für Shared Space. 2017. Available online: https://www.forschungsinformationssystem.de/servlet/is/375490/ (accessed on 21 October 2019).

20. Pressl, R. Parking Management and Incentives as Successful Strategies for Energy-Efficient Urban Transport; Technical Report from FGM-AMOR: Graz, Austria, February 2017.

21. National Highway Traffic Safety Administration (NHTSA). Notices and Final Rules: Low Speed Vehicles. 49 CFR Part 571 Federal Motor Vehicle Safety Standards, Low Speed Vehicles; National Highway Traffic Safety Administration: Washington, WA, USA, 2008.

22. Grundy, C.; Steinbach, R.; Edwards, P.; Green, J.; Armstrong, B.; Wilkinson, P. Effect of 20 mph traffic speed zones on road injuries in London, 1986-2006: Controlled interrupted time series analysis. BMJ 2009, 339, 4469. [CrossRef] [PubMed]

23. Sugiyanto, G.; Malkhamah, S. Determining the maximum speed limit in urban road to increase traffic safety. J. Teknol. 2018, 80, 67-77. [CrossRef]

24. Aldred, R. Motor traffic on urban minor and major roads: Impacts on pedestrian and cyclist injuries. In Proceedings of the Institution of Civil Engineers-Municipal Engineer; ICE Virtual Library: London, UK, 2019; Volume 172, pp. 3-9.

(C) 2019 by the authors. Licensee MDPI, Basel, Switzerland. This article is an open access article distributed under the terms and conditions of the Creative Commons Attribution (CC BY) license (http://creativecommons.org/licenses/by/4.0/). 